\title{
1. Leadership and individualism
}

The West is in the cold season of excessive individualism and yearns for the warmth of community to allow human relations to blossom.

(Etzioni, 1993, p. x)

As described in the introduction it seems that concepts of leadership shift between individualistic and distributed perspectives that are reflected in the duality of notions of society [Gesellschaft] and community [Gemeinschaft]. A push towards Gesellschaft and ideas of society develops ideas of individualism in leadership studies and a push towards Gemeinschaft and concepts of community develops ideas of a distributed nature when discussing leadership. As also pointed out in the introduction there appears to be a propensity in contemporary writing on leadership that errs towards the individual. On the surface, therefore, taking a community perspective on leadership, as this book does, might redress the balance. However, as we shall see in this chapter, the issue of individualism and community is a little more complex. For instance, individualism can be seen as integrated into concepts of community (Delanty, 2003 [2010]) and that what we witness then is a dynamic duality of individualism within and about concepts of community. In Durkheim's (1897 [1951]) work (cited in Gusfield, 1975, p. 15) he suggests that organic solidarity could not be sustained without risk to the individual personality. Also Lichterman (1996) proposes community relies heavily on ideas of individuality. Other writers (for example, Sandal, 1982; Schaar, 1983) have also highlighted that the self is constituted by community (for example, Corlett, 1989; MacMurray, 1996).

Moreover, MacMurray (1996) says that the development of the individual is the development with his or her other. He explains this by underlining that we are part of that from which we distinguish ourselves; hence if we see ourselves as individuals outside larger groups or communities, there is still the relationship with the group by this separation. He draws this out further by using a religious example of solitude where he suggests that the withdrawal into self 
is an affirmation of personal dependence not an escape from the relationship with the other. While keeping MacMurray's comments in mind, the chapter explores differing conceptualizations of individualism. Dipping into the literature on individualism will help to uncover a level of complexity that does not appear apparent when looking at the leadership literature.

\section{INDIVIDUALISM}

Perhaps people do not make distinctions between leaders and the institutions they lead.

(Gans, 1988, p. 41)

Gans (1988) elaborates on the quote above by suggesting that chief executive officers (CEOs) of organizations and presidents of countries do not achieve organizational successes by themselves, yet they are often given historical immortality as doing so. This is indicative of the individualistic perspectives of leadership that pervade the literature (Grint, 2005b; Jackson and Parry, 2008; Knights and O’Leary, 2005, 2006), where leadership studies concentrate on the behaviour, personality or style of particular individuals deemed to be leaders defined by their role (Balkundi and Kilduff, 2006; Friedrich et al., 2014). Individualism, though, as Gans points out, comes in varying guises. At a basic level, he recommends that it is the pursuit of individual freedom and of personal control over environmental factors, the ability to make decisions in social settings. He also describes it, however, as an ideology, one that seems to have gripped the US culture. From this early point, we might relate the leadership literature's link to individualism as one derived from the American focus that the empirical and conceptual literature has enjoyed for many years (Burns, 2005). Individualism has come to mark modernity and as Scott Lash proposes, the 'We' of modern times 'has become a set of abstract, atomized individuals' (1994, p. 114). In this vein Gans (1988) also advises that individualism of 1980s America was associated with capitalism, and that individualistic values play a larger role during periods of prosperity. But Gans also links individualism to personal development, a link to leadership discussed further below, and warns against confusing individualism based on personal development with selfishness and greed. In this sense, he 
suggests that individualism is attacked for having a harmful effect on community. These attacks, he says, propose that individualists deprive themselves of many financial and social benefits of community. He goes on to argue, though, that individualism is social, implying that we can only survive as individuals because we are in and of society, as expressed in the opening section to this chapter. He also critiques the over-idealistic perceptions of community put forward by some writers (for example, Bellah, 1985), which suggest a quasi-religious existence. This relational notion of individualism and community is the general focus of this book and needs further exploration in relation to leadership. The focus of the book will also help to identify areas when this can be further elaborated. But first it appears important to refer to the work of Paul Lichterman owing to his views around ideas of personalism and individualism. These ideas enable a broader perspective of individualism and its relation to community to be taken.

\section{PERSONALISM}

Early on in Paul Lichterman's (1996) book, The Search for Political Community, he makes a distinction between what he calls 'instrumental or utilitarian individualism' and 'personalism'. Instrumental individualism, he indicates, is the easier individualism to identify in society. This is where individuals build affluent lifestyles through careful calculation. What he describes as 'personalism' is more akin to the ways of speaking or acting that highlight a unique, personal self. It is personalism with which Lichterman is concerned when discussing individualism and community and stresses it as seeking self-fulfilment and individualized expression. He proposes that personalism is interested in growth through personal development as opposed to growth through material means. He acknowledges that within personalism there is a supposition that individuality has inherent value and upholds the personal self and that this has been criticized as being overly narcissistic and self-centred. Although personalism has this orientation towards upholding the self and is often in tension with community ideas, Lichterman contends that this is not at the expense of community ideas, but is in relation to community. For example, he describes individuality as not pre-existing culture but being a cultural accomplishment and personalism is 
developed in a kind of community that emphasizes norms of highly individualized expression.

Lichterman's main thesis therefore is to imply that personalism plays a role in the construction of community ideas and suggests that this could be 'at best' a counterweight to community ideals and 'at worst' a looming threat. He believes previous writers (for example, Bell, 1976; Lasch, 1979; Rieff, 1966) have failed to recognize any positive impact of personalism on aspects of community and instead paint a picture of hedonistic personalism taking over culture. At this juncture it is worth reflecting on whether this is how leadership theory is being portrayed. Leadership theory could be framed as being painted as the hedonistic personalism in a reactionary way due to the lack of cultural and community perspectives. Maybe the discussion needs to critically reflect on this and advocate, as Lichterman does, a counterweight perspective. One could argue, for instance, that the criticism of leadership from an individualistic perspective (for example, Knights and O'Leary, 2006) and indeed perspectives on toxic and bad leadership (Kellerman, 2004; LipmanBlumen, 2005) 'assume leadership' (Ahonen et al., 2012), in the sense that they label people in positions of power as leaders, whether they are seen by those around them 'as leaders' outside their role or not.

When considering criticism levelled at leadership theory, suggesting that is of an individualized nature, it would appear that while some writers are discussing this in terms of instrumental individualism (for example, Knights and O'Leary, 2005, 2006), others describe it more in terms of narcissistic personalism (for example, Ford et al., 2008). There is further a wealth of leadership development approaches based on ideas of self-development (for example, Edwards et al., 2002), to the extent that leadership development is a proxy for self-development. Additionally there are the increasing ideas of the authentic self as effective leadership (for example, Avolio and Gardner, 2005; Avolio et al., 2004; Bass and Steidlmeier, 1999; Caza and Jackson, 2011; Gardner et al., 2005, 2011; George, 2003; Luthans and Avolio, 2003; Shamir and Eilam, 2005; Walumbwa et al., 2008; Yammarino et al., 2008). All these aspects of leadership are being debated in the literature but are not explicitly addressing ideas such as Lichterman's discussion on personalism (hedonistic, narcissistic or otherwise) and instrumental individuality. From this point, therefore, ideas of and critics of ethical, authentic or toxic or bad leadership may benefit in their conceptual development from 
making use of the concept of personalism and/or instrumental individuality.

Moreover, this discussion regarding individualism, personalism and community seems to suggest taking a more relational perspective. This is similar to ideas being developed in the leadership literature on a relational perspective (for example, Cunliffe and Eriksen, 2011; Uhl-Bien, 2006). From this perspective leadership is seen as intersubjective - 'as a way of being-in-relation-to-others' (Cunliffe and Eriksen, 2011, p. 1430, emphasis added) and recognizes the importance of the relationship (Gergen, 2009) as opposed to the individual only. It seems, then, to take a community perspective on leadership is to take a relational perspective. Yet, what a community perspective appears to be adding in this instance is a deeper sense of the individual in relation to community and hence to ideas of leadership.

If we take this perspective, therefore, we might see ideas of leadership, such as servant leadership (Greenleaf, 1977), as too idealistic, and reflect on the individual in relation to leadership and followership and again then in relation to community. For example, Lichterman (1996) uses the case of volunteering in the community that, on the surface, is seen as an unselfish act, a case of servant leadership maybe, yet he also states that the person volunteering also gets something out of the relationship with the community - a sense of fulfilment. Maybe we should reflect back on those we construct as leaders and not be too surprised that they may get something from the leader-follower relationship too. This would serve to say that some ideas of leadership, such as servant leadership, are too idealistic in the sense that they go too far towards followership and that a relational view might rein this back a little towards understanding what the individual leader or indeed individual follower is getting out of the relationship and how this is moderated by the relationship with the context. Without taking a relational perspective we tend towards the individual leader or follower but without understanding their motives and hence their personalism. As Keith Grint (2010a, p. 22) says:

leaders are not heroic knights on horseback rescuing damsels in distress, they are instead . . . figures, fighting . . . their own demons.

Although I have taken this slightly out of the context in which Grint discusses leadership, I do see this exemplifying the idea that we tend 
to reflect too much on and/or construct the leader as the heroic, as Ford et al. (2008) suggest and is core to criticism of individualistic concepts of leadership, levelled by other scholars (for example, Knights and O'Leary, 2006). This very criticism, however, has a tendency to perpetuate an inherent heroic perspective and does not account for or explore a level of personalism in the role of leader to which this criticism is aimed. There is hence a lack of knowledge of these individuals and the extent to which they are, as Grint describes it, 'fighting their own demons'. Without such additional exploration, we are in danger of developing characters and caricatures of leaders in society whereby we construct the heroic figure without understanding their personalism.

\section{CHARACTERS AND CARICATURES OF LEADERSHIP}

Following on from the discussion above, this section develops a critical theme around ideas of leadership represented as character and caricature. The role of characterization in more general studies of culture and community has been criticized for being an inaccurate representation of individuals (Urban, 1996). In Urban's view this is owing to a lack of connection between the sensible (being perceptible by the senses) and the intelligible (having meaning). Characterization, he suggests, breaks the link between perception and knowledge of social interaction. Yet as Agamben (1993, p. 34) points out, 'whatever being always has a potential character', and the process of characterization in this sense could reflect Agamben's idea of being-in-act and implies potentiality. Agamben links this to the ethical (which I discuss in more detail in Chapter 6) whereby he recommends that the only experience of the ethical is the experience of being one's own potentiality and possibility. This appears to resonate with notions of leadership that reflect a representation of the leader as ultimately being oneself and developing those about them to know and be themselves (for example, Goffee and Jones, 2000).

The literature has already recognized this issue in relation to leadership and management being disembodied through character (for example, Ropo and Parviainen, 2001; Ropo and Sauer, 2008; Sinclair, 2005). The suggestion is that leadership study is lacking a bodily and sensory connection through experience (Ropo and 
Parviainen, 2001). Furthermore, Sinclair (2005) has suggested that there is a lack of appreciation of bodily aspects such as gestures, stature, posture and voice in management education. The suggestion therefore is that a deeper reflection on the process of characterization is worth pursuing in relation to the study of leadership. Through an exploration of leadership as community, themes around the construction of leaders as characters can be uncovered. For instance, the performativity of certain concepts in the leadership domain, such as authentic (for example, Avolio and Gardner, 2005), ethical (for example, Mendonca and Kanungo, 2007), transformational (for example, Bass and Riggio, 2006) and charismatic (for example, Conger and Kanungo, 1987; House, 1977), pressurize not just those aspiring to be leaders (cf. Ford et al., 2008) but also those searching for leaders or being pressurized to search for leaders, to search for a particular character. This is to the extent that we might construct fellow workers as these characters similar to how Alvesson and Spicer (2010) describe metaphors of leaders as saint, sinner, buddy, gardener, commander or cyborg. The suggestion, therefore, is that this characterizing is enhanced through the performativity of such concepts in the literature that also causes society to further disembody leadership and turn it into a caricature.

MacIntyre's (1984 [1991]) work - After Virtue - seems to be a good place to start in the exploration of leader as character. For example, MacIntyre (1984 [1991], p. 30) describes the manager as character:

... the obliteration of the distinction between manipulative and nonmanipulative social relations ... [and is] not able to engage in moral debate.

Drawing on MacIntyre, I argue that the 'character' of leader may suffer the same fate as being popularized within contemporary business literature (see Ford and Harding, 2007 for a critique) may have developed certain characters that are constructed as inherently moral or inherently immoral. These issues thus bring into question the very use of the leadership discourse in business organizations. The argument therefore is that for the concept of leadership to 'fit' organizations, it is developed into a character role format as if written into a play. This procedure consequently disembodies leadership from reality and hence suggests a fate of becoming caricatured. This seems a reasonable proposition given Weber's ideas of 
'ideal-type' (Weber, 1949, cited in Gusfield, 1975). Weber's idea of 'ideal-type' is as described by Gusfield as an imagined construct and described by Weber (1949) as:

... not a description of reality but it aims to give unambiguous means of expression to such a description.

Gusfield (1975) explores this with reference to the concepts of 'bureaucracy', 'capitalism' and 'community'. He suggests that idealtypes are 'heuristic tools, helpful in understanding reality but in themselves not a version of real situations' (Gusfield, 1975, p. 13). In this description Gusfield highlights the danger of using idealtypes - reification - in treating an abstract, analytical term as if it were descriptive and empirical. This is what happens when tagging occurs in leadership studies, for example, using an ideal-type to try and describe certain 'forms' of leadership, such as ethical leadership. The outcome of this tagging is a reification of ideas of leadership that then develops into a process that can be described as characterizing and caricaturing. For instance, relating leadership and leaders to metaphors, as do Alvesson and Spicer (2010), promotes a caricatured viewpoint on leadership by highlighting exaggerated views on leader identities.

Maffesoli (1996) also writes about the idea of 'ideal-type' but he uses the notion of persona or changeable mask. He takes a more dramaturgical sense in his writing, suggesting that the idea of the changeable mask 'blends into a variety of scenes and situations whose only value resides in the fact that they are played out by the many' (Maffesoli, 1996, p. 10). This resonates with leadership as a mask, discussed further in Chapter 4 and paraphrased a little here. The additional idea could also be that leadership is a persona to be played out in differing situations. Interestingly, Maffesoli goes further and proposes that emblematic figures such as saints and heroes act as ideal-types, they are, however, "empty "forms", matrices in which we may all recognize ourselves and commune with others' (1996, p. 10). Leadership therefore could also be seen as an empty form to which we relate to recognize ourselves and that this is historically driven through the story making of the heroic (Ford et al., 2008).

To develop the idea of 'character' further we might link it to ideas of community, and, particularly, symbolic representation of 
community. For instance, Gusfield highlights the idea of symbolic construction, which refers to 'a process of creating and signifying the existence and character of persons and objects by the ways in which human beings conceptualize, talk about and define them' (Gusfield, 1975 , p. 24). I have briefly discussed ideas of symbolic representation in relation to the leadership literature previously (Edwards, 2011) whereby leadership is represented by symbolism of and from community. I continue this discussion in Chapter 4, but here we can briefly emphasize images of good and bad as metaphors (for example, Alvesson and Spicer, 2010), from religious forms of 'the saint' and 'the sinner' to the dualist notions of 'the good deity' and 'the evil deity', to more contemporary comic book iconography of 'the hero' and 'the villain' (see Edwards et al., forthcoming a). This idea of leadership represented through symbolism appears to resonate with the idea of 'character' in that if one is to take a community perspective, then the character of leadership is represented through the symbolism within the community. As I show in Chapters 4 and 6 , ethicality and the representation of leadership are enacted through symbolic community representation. The argument is that this symbolic representation disembodies leadership through the process of abstraction and tends to progress further to become caricature.

Interestingly, scholars have linked leadership to caricature relatively early on. Hollander and Julian (1969, p. 388) made the following observation:

... two research emphases represented by trait and situational approaches afforded a far too glib view of reality. Indeed, in a true sense, neither approach ever represented its own philosophical underpinning very well, and each resulted in a caricature.

Hollander and Julian's paper does not explore this much further and this book seeks to make a contribution here by developing the theme. For example, the continued process from 'character' to 'caricature' of leadership through being tagged is well articulated again by Gusfield in the work of Cobban (1964) concerning the French Revolution. Gusfield highlights Cobban's conclusions regarding the view that the French Revolution was a 'bourgeois' revolution. As Gusfield (1975, p. xx) paraphrases:

Such views of social structure were not those of the actors of the time. Instead, he asserts they are the ways in which the historians and 
sociologists utilize contemporary perceptions and concerns to build a mythical past and affirm their commitment to a particular impact of the French Revolution as a myth which governs the present.

This example enables us to make the link from character to caricature whereby the further away from the 'actors of the time' the further we characterize and then eventually caricature concepts such as leadership in a social setting. For instance, reading Learmonth $(2005$, p. 620$)$ there is a quote used from the research that reflects this:

... just as a caricature I would make the observation that many administrators in the $70 \mathrm{~s}$ and $80 \mathrm{~s}$ the top ones were employed mainly, well mainly, for their brain power per se as I say a lot of them were intellectual Oxbridge graduates and so on.

The notion of leader or leadership as caricature appears to resonate with Agamben's 'dumb silence of the comic body' (1993, p. 47), whereby leadership as an idea is made dumb or silenced through a process of parody.

\section{COSTUME AND LEADERSHIP}

To develop notions around character further there are other, more theatrical, references that can be made, such as social drama (discussed later in the book), the stage set in the sense of place and space (also discussed later in the book). An interesting addition to these perspectives, however, is costume. For the development of this theme I draw on Joanne Ciulla's (2013) work on critically reviewing, through historiography, the leadership of Nelson Mandela. First, she highlights that Mandela saw himself as an actor playing various roles, which relates to the ideas of character and caricature discussed above. Ciulla discusses in detail Mandela's life story as the basis for his authentic leadership (for example, Shamir and Eilam, 2005) and particularly elaborates on Mandela's apparent enjoyment in playing various roles, which Ciulla uses to question the concept of authentic leadership. If one is playing a role, to what extent are we able to be genuine or authentic? Of further importance here is Ciulla's (2013) description of Mandela's seeming obsession with his appearance and more specifically with dress. His appearance appears extremely important to him throughout his life: 
One oddity about Mandela and biographies of Mandela is the amount of attention Mandela and other writers give to his clothing. For Mandela, dressing well and dressing right for the occasion are important aspects of how he sees and presents himself to the world.

(Ciulla, 2013, p. 166)

Ciulla goes on to describe how this connection to dress was developed through appreciating smart suits worn by a chief with whom he lived and the connection Mandela recognized between dressing like a white man and being equal to one. Ciulla uses biographical evidence to stress the meticulous nature in which Mandela dresses and ensures he is 'dressing the part' in major events in his life. This culminated, as Ciulla describes, in him wearing the shirt of the Springbok rugby team at the 1995 rugby world cup final, an episode that now immortalizes the Rainbow Nation. It looks as if various 'costumes' enabled him to create various characters that included that of lawyer, revolutionary leader, the 'Black Pimpernel', president and grandfather. Herein, therefore, we see evidence of an important link between leader, costume and the creation of character. Ciulla concludes by asking - Who is Nelson Mandela? In response, she states that he was a great symbol and 'an enigmatic person who emerged from prison accustomed to concealing his emotions behind a mask' (Ciulla, 2013, p. 168). These concluding points about Nelson Mandela's concealment of emotion behind a mask seem to resonate with issues of leadership and symbolism in that the mask is a symbolic representation of the leader and reinforces the character through costume.

\section{LEADERSHIP AS ROLE}

Last, the reflections on individualism, character and costume also appear to help with the notion of leader as a role or a position. Urban (1996), for example, describes a role as a 'bundle of rights and duties' (p. 118), it seems leadership studies has been searching for the exact bundle of rights and duties for leaders, maybe we are better to think of the rights and duties of numerous roles of leadership in a shifting pattern of social engagement. Additionally, Urban asks the question as to whether individuals act out roles owing to the way they want their lives narrativized or whether they play out these roles according to how they have previously narrativized a future. 
This appears to be an interesting perspective for leadership, to what extent do individuals play out roles of 'the leader' based on internal reflection of self or internal reflection on a future self.

Urban also highlights the roles of 'ceremonial fathers' and 'ceremonial mothers'. These are roles played out in certain indigenous communities and are not the real mother and father but representations of those kinship links within a ceremonial space. This begs the question as to whether leaders are seen as roles reminiscent of ceremonial mothers and fathers within the ceremonial space of the organization or social grouping. Urban goes on to feature the work of Sullivan (1988), who talks about the centre of a ceremonial space where individuals gain the most direct contact with the sacred and the divine. This seems to resonate with ideas of leadership generally (Grint, 2010b), but also with ideas of the charismatic (Weber, 1947). Leadership therefore is created as a ceremonial space within organizations where one can meet the sacred and divine and this is transgressed onto expected roles of leaders in organizations, hence furthering the character and caricature process. This also appears to link to a discussion held later in the book around leadership and social drama (see Chapter 5).

\section{SUMMARY}

This chapter has explored ideas about individualism, personalism, character, costume and community and it looks as if ideas of leadership appear to be constructed in context from an interplay between ideas of the individual, the culture representation of individualism, personalism and the context. Laurie Lee describes this interplay a little when he describes an outing as a small boy in his book Cider with Rosie:

Everything began to appear comic strange ... We began to look round fondly at our familiar selves, drawn close by this alien country.

(Lee, 1959, p. 193)

This quote aptly describes the conclusions one can make from this chapter in the sense of ideas of the 'familiar self' through personalism, towards ideas of relational aspects between each other, in the sense of looking towards others' 'familiar selves' and, last, how 
all this interacts with the context and culture - 'the bringing closer through alien context' experiencing community and society. Leaderfollower relationships, therefore, may be developed through this complex multitude of interactions with the self, others, context and culture. In the remaining chapters we shall take a deeper look at these interactions. 